\title{
Synthesis and Structure of Lower Rim C-Linked N-Tosyl Peptidocalix[4]arenes
}

Sofiane Ben Sdira, Caroline P. Felix, Marie-Béatrice A. Giudicelli, Pascal F. Seigle-Ferrand

Monique Perrin, Roger J. Lamartine*

\section{Supporting information}

Figure S1. (a) ${ }^{1} \mathrm{H}$ NMR (300 MHz) spectrum of 7g in DMSO-d 6 ; (b) ${ }^{1} \mathrm{H}$ NMR (300 MHz) spectrum of $7 \mathbf{g}$ in $\mathrm{CDCl}_{3}$.

Figure S2. (c) ${ }^{1} \mathrm{H}$ NMR (300 MHz) spectrum of 6a in DMSO-d 6 ; (d) ${ }^{1} \mathrm{H}$ NMR (300 MHz) spectrum of $\mathbf{6 a}$ in $\mathrm{CDCl}_{3}$. 
(a)

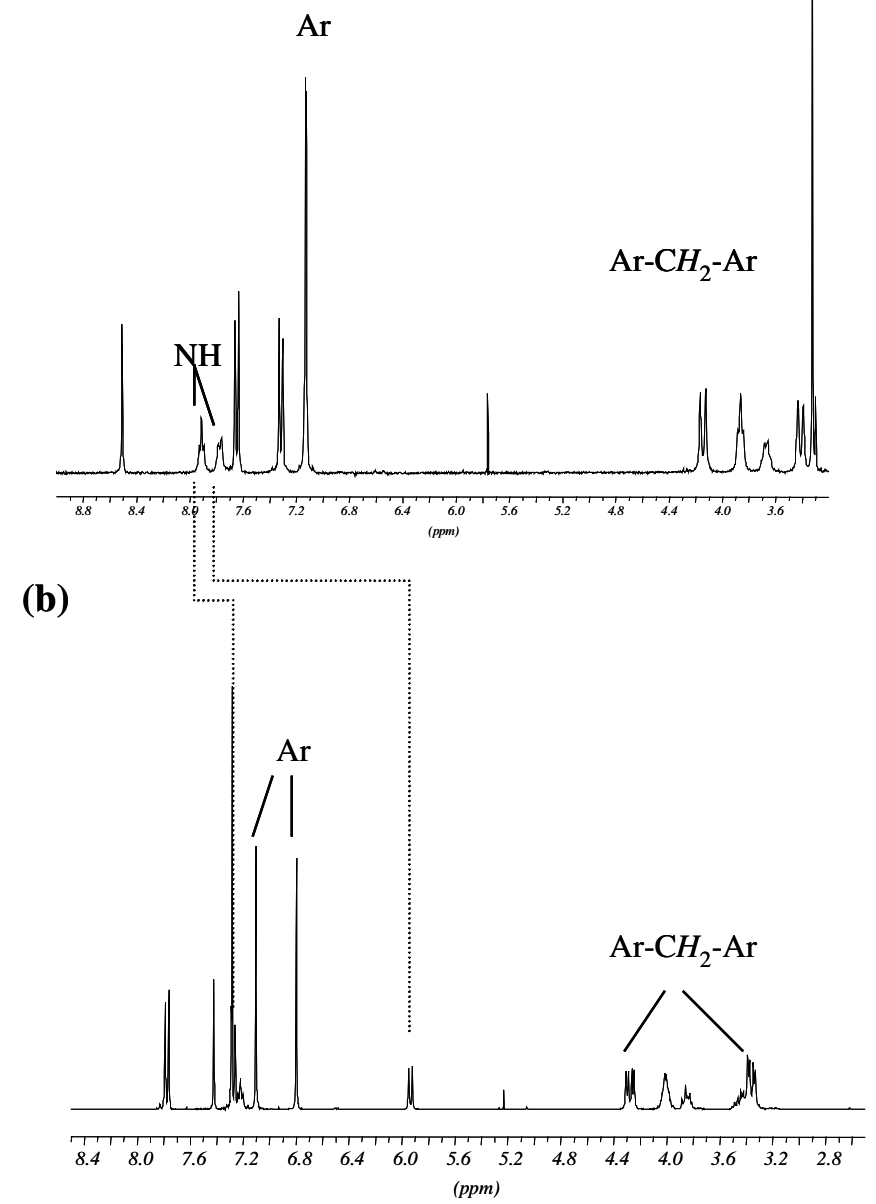

Figure S1. (a) ${ }^{1} \mathrm{H}$ NMR (300 MHz) spectrum of 7 g in DMSO-d 6 ; (b) ${ }^{1} \mathrm{H}$ NMR (300 MHz) spectrum of $7 \mathbf{g}$ in $\mathrm{CDCl}_{3}$. 
(c)

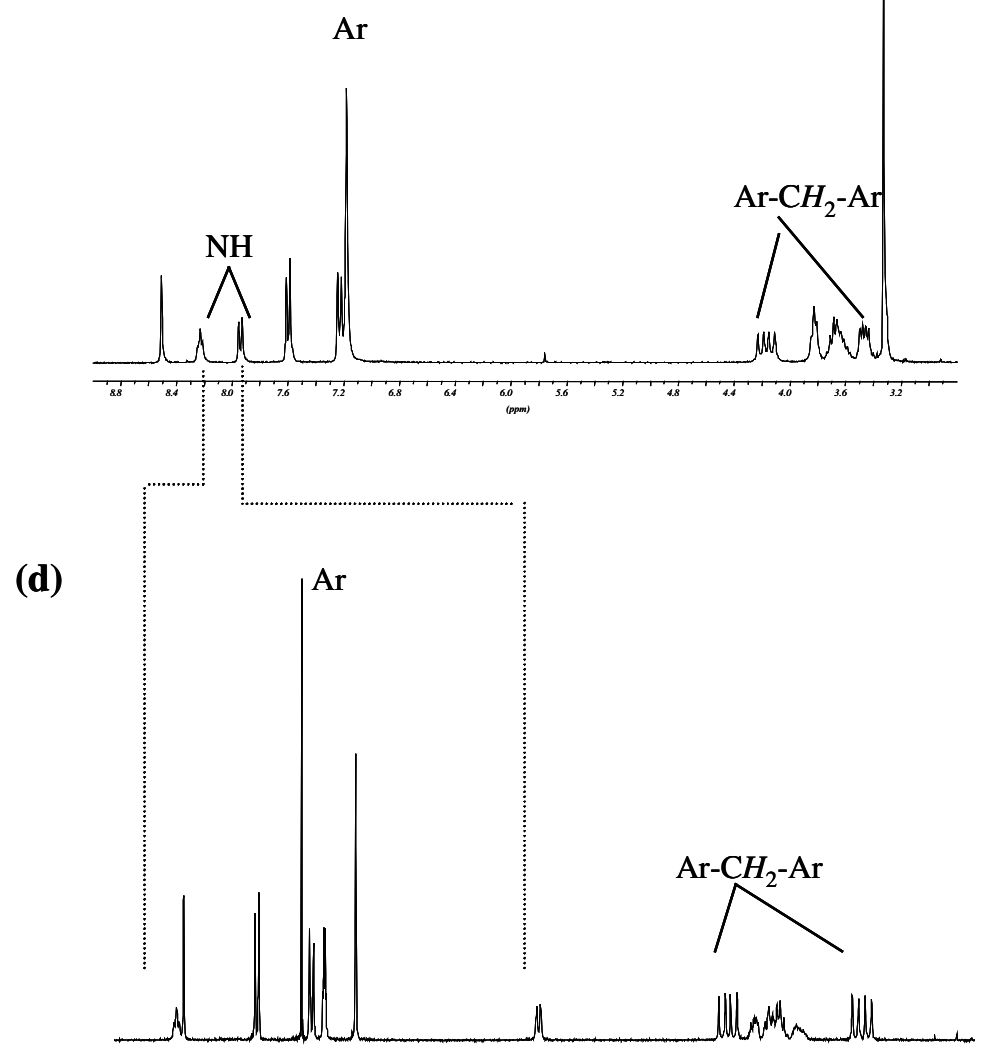

Figure S2. (c) ${ }^{1} \mathrm{H}$ NMR (300 MHz) spectrum of 6a in DMSO-d ${ }_{6}$; (d) ${ }^{1} \mathrm{H}$ NMR (300 MHz) spectrum of $\mathbf{6 a}$ in $\mathrm{CDCl}_{3}$. 